\title{
(2) OPEN ACCESS \\ Subclavian artery laceration following clavicle fracture, successfully treated with a combined endovascular and open surgical approach
}

\author{
Samuel Arnold, ${ }^{1}$ Darina Gilroy, ${ }^{2}$ Peter Laws, ${ }^{1}$ Josh Kempthorne ${ }^{2}$
}

\begin{abstract}
'Department of Vascular and Endovascular Surgery, Christchurch Hospital, Christchurch, New Zealand ${ }^{2}$ Department of Orthopaedic Surgery, Christchurch Hospital, Christchurch, New Zealand
\end{abstract}

Correspondence to Dr Samuel Arnold; arnsa368@otago.ac.nz

Accepted 2 April 2021
D) Check for updates

(c) BMJ Publishing Group Limited 2021. Re-use permitted under CC BY-NC. No commercial re-use. See rights and permissions. Published by BMJ.

To cite: Arnold S, Gilroy D, Laws $\mathrm{P}$, et al. BMJ Case Rep 2021;14:e241382. doi:10.1136/bcr-2020241382

\section{SUMMARY}

Subclavian artery injury is a rare complication of clavicle fracture. The fractured clavicle can lacerate the underlying subclavian artery. Life-threatening haemorrhage can occur secondary to arterial laceration, and if distal blood flow is impaired, upper limb ischaemia can develop. There is little discussion in the literature regarding combined (or 'hybrid') endovascular and open surgical management of acute subclavian injuries secondary to clavicle fracture. We report a case of subclavian artery laceration secondary to clavicle fracture, managed with a combined endovascular and open surgical approach. An endovascular balloon was used for proximal arterial control, while surgical exposure and primary repair of the subclavian artery was completed, followed by fixation of the clavicle. There was no sustained vascular or neurological impairment at follow-up. We suggest that select traumatic injuries of the subclavian artery can be safely and successfully managed with a combined endovascular and open surgical approach.

\section{BACKGROUND}

Fracture of the clavicle accounts for approximately $2.6 \%-4 \%$ of adult fractures. ${ }^{1}$ Associated vascular injuries are rare, occurring in less than $1 \%$ of cases. ${ }^{12}$ However, recognition and treatment of arterial injuries in the context of clavicle fractures is critical, as they can result in life-threatening haemorrhage, or limb-threatening ischaemia. ${ }^{1} \mathrm{We}$ report a case of a 46-year-old man who fell from a road bike, sustaining a lateral impact to his right shoulder. This resulted in a comminuted right clavicle fracture complicated by laceration of the right subclavian artery, which was successfully treated with a hybrid endovascular and open surgical approach.

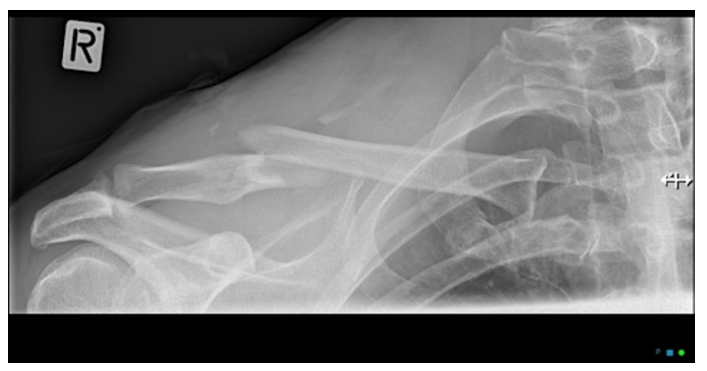

Figure 1 Anteroposterior X-ray of right shoulder demonstrating clavicle fracture.

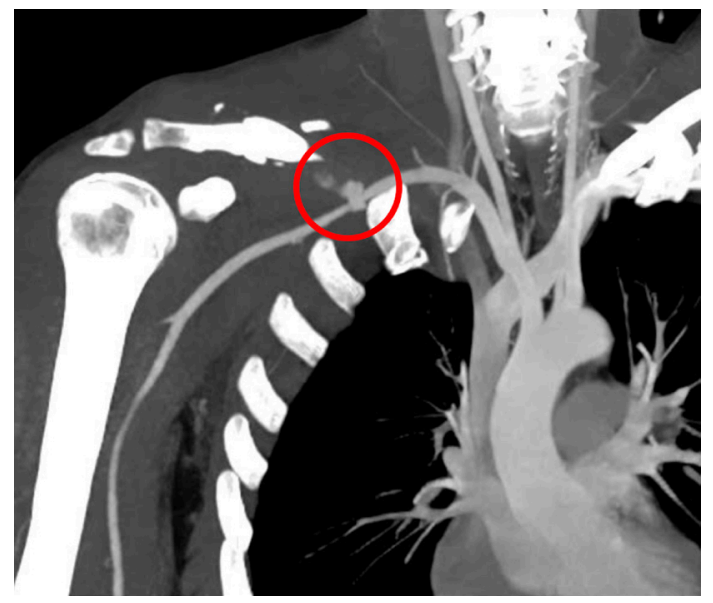

Figure 2 Coronal CT angiogram slice demonstrating contrast extravasation from the right subclavian artery (circled).

\section{CASE PRESENTATION}

An otherwise healthy 46-year-old man presented to our Emergency Department (ED) after falling from a road bike, landing heavily on his right shoulder. On arrival, he described pain in his right shoulder. Examination revealed a closed deformity of his right clavicle. He was haemodynamically normal and stable, with a well-perfused right arm and palpable radial pulse. An anteroposterior X-ray of his right shoulder (figure 1) revealed a comminuted fracture of the clavicle with a small 'butterfly' fragment inferiorly.

Within $30 \mathrm{~min}$ of presenting to our ED, the patient developed a massive non-pulsatile haematoma over the fracture site, out-of-keeping with 'normal' postfracture swelling and bruising. This examination finding prompted suspicion for an associated vascular injury. Radial and brachial pulses remained palpable. The patient reported some subjective tingling in all digits, but assessment of power and sensation in the distribution of all peripheral nerves remained normal. An urgent CT angiogram (CTA) of the chest and right arm revealed active haemorrhage from the third part of the right subclavian artery (figure 2), along with minimally displaced posterior fractures of the first and second ribs. Notably, both the superior and inferior parts of the injured arterial segment showed contrast extravasation, raising concern for complete arterial transection. Contrast was seen passing into the axillary artery. There was no haemothorax or 


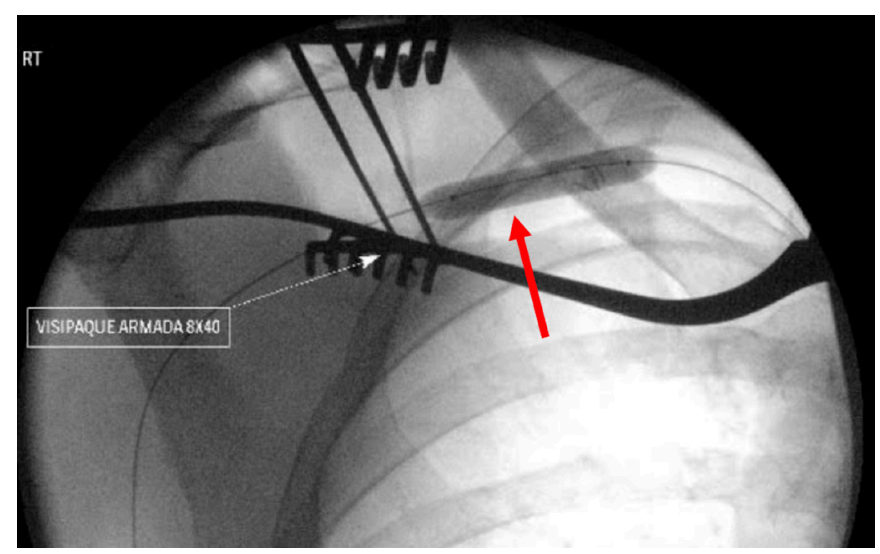

Figure 3 Angiogram demonstrating positioning of balloon in the right subclavian artery. The balloon is indicated by the red arrow.

tracheobronchial injury. Haemoglobin was within the normal range $(131 \mathrm{~g} / \mathrm{L})$ and coagulation studies were normal.

\section{INVESTIGATIONS}

Initial X-ray (figure 1): Demonstrates the clavicle fracture.

Computerised tomography (figure 2): Demonstrates the subclavian artery laceration.

Intraoperative angiogram (figure 3): Shows inflated endovascular balloon in right subclavian artery.

Six-week follow-up X-ray (figure 4): Demonstrates plated clavicle with early callous formation.

\section{TREATMENT}

The patient was immediately transferred to the operating theatre under the combined care of our Vascular, Interventional Radiology and Orthopedic teams, and a general anaesthetic was administered. A percutaneous puncture of the right groin was made to access the right common femoral artery (CFA). A 9 French sheath was placed within the CFA. An endovascular catheter and guide wire were inserted and manipulated proximally through the aorta, through the brachiocephalic trunk, into the right subclavian artery. An angiogram demonstrated contrast extravasation from the third part of the subclavian artery, corresponding to the injured segment seen on the CTA. The wire and catheter were able to be passed across the injured segment. An intravascular position was again confirmed by repeat angiography. The catheter was then removed. An $8 \times 40 \mathrm{~mm}$ Armada balloon was introduced over the wire and inflated proximal to the injury (figure 3 ) to achieve proximal control. Contrast flow into the injured segment of subclavian artery ceased.

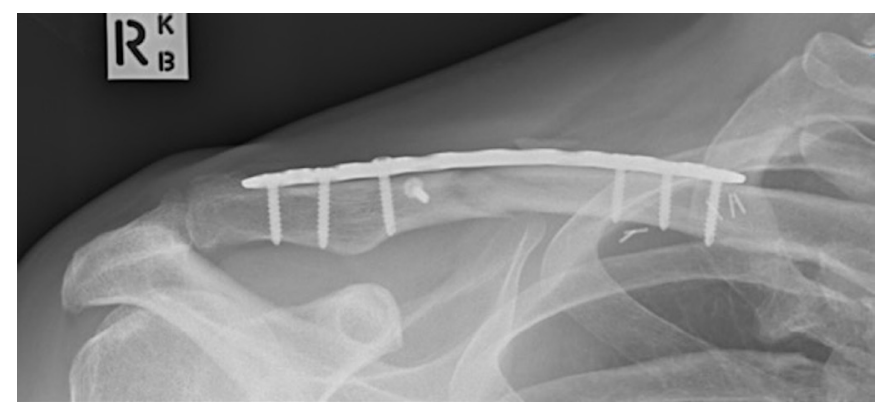

Figure 4 Follow-up clavicle X-ray demonstrating early callous formation.
With proximal control achieved, the surgical approach to the clavicle was made. An oblique incision centred over the fracture site was made along the anterosuperior border of the right clavicle. Subcutaneous flaps were created anteriorly and posteriorly, and the incision was extended to facilitate mobilisation of the fracture fragments and access to the subclavian artery. Extensive interstitial and intrastitial haematoma was present, but no active haemorrhage was observed. Further dissection around the artery allowed identification of the injured segment. The arterial wall had two full-thickness lacerations, one superior and one inferior, suggesting the clavicular fragment had stabbed through, although it was not completely transected. Proximal and distal control was then achieved with slings, the balloon was deflated and arterial clamps were applied. Both lacerations were then successfully primarily repaired with 5-0 prolene sutures.

Interfragmentary fixation of the clavicular butterfly fragment was achieved using a lag screw technique with a $2.7 \mathrm{~mm}$ screw. A Stryker VariAx locking plate was applied superiorly to achieve reduction and the final position of the metalware confirmed on fluoroscopy. ${ }^{3}$ The fascial and soft tissues were closed in layers, with 3-0 monocryl closure of the skin, and a simple occlusive dressing applied.

\section{OUTCOME AND FOLLOW-UP}

The patient remained haemodynamically stable throughout the operation, and on waking had no signs or symptoms of neurovascular injury. He was able to be discharged home on the first postoperative day. Aspirin (100 mg once daily) was prescribed for 6 weeks following the primary arterial repair.

The patient undertook a standard rehabilitation protocol, consisting of immobilisation in a broad arm sling for 6 weeks and commencing gentle pendulum exercises at the 2 weeks postoperative mark. At the 6 week postoperative follow-up in our orthopaedic outpatient clinic, he was discharged to the care of physiotherapy to commence aggressive range-of-motion exercises and gradual strengthening. At time of discharge from physiotherapy, he was 12 weeks post injury, and had recovered a full painless range of motion through his right shoulder, was neurovascularly intact and had returned to work in an office-based job. An X-ray completed at 6 weeks postoperatively demonstrated early callous formation (figure 4).

\section{DISCUSSION}

Current literature favours primary endovascular repair (such as stent placement) of traumatic subclavian artery injuries in haemodynamically stable patients. Endovascular approaches have the advantage of being less invasive than open surgery, are associated with reduced intraoperative blood loss, improved in-hospital mortality, and shorter hospital stay. ${ }^{4}$ Five-year patency rates for stenting procedures are approximately $82 \%{ }^{5}$ However, complete vessel transection has been described in some reports as a cause for endovascular treatment failure in acute trauma, primarily because crossing the injury can be technically challenging. ${ }^{6-8}$ In our case, our preoperative imaging showed active contrast extravasation from both the superior and inferior aspects of the subclavian artery, raising concern for complete arterial transection which may have not been amenable to endovascular management alone. This contributed to our decision for a combined endovascular and open approach.

A hybrid endovascular and open surgical approach for subclavian artery repair has been described in case reports previously; however, only for the repair of aneurysms, not to our knowledge in the context of acute arterial trauma secondary to clavicle 
fracture. ${ }^{9}$ These cases describe a similar technique to the one used in our case, with balloon occlusion used to establish proximal control, followed by open repair of subclavian artery aneurysm. In these cases, the combined endovascular and open technique reduced the size of the dissection field required to achieve arterial control, suggesting a possible reduction in morbidity related to reduce risk of injury of adjacent structures with this technique. Furthermore, these reports suggest endovascular control prior to open repair results in minimal active haemorrhage during the repair, in turn reducing intraoperative blood loss, improving the surgical field, reducing the risk of iatrogenic neurovascular injury and improving the accuracy of the repair itself. ${ }^{10}$ We found this to be true in our case, even in the previously unreported context of acute subclavian artery trauma secondary to clavicle fracture. Our case also suggests a combined approach has further utility in the trauma setting, as haemorrhage into surrounding tissue

\section{Patient's perspective}

Paraphrased from the 6-week follow-up:

The operation was well-explained prior to 'going to sleep' (administration of general anaesthetic), which was confidence inspiring.

Movement is not currently painful or stiff, and there are no lasting issues with my arm or shoulder.

Very pleased with the outcome overall, after an intimidating situation.

\section{Learning points}

- Subclavian artery laceration is a rare but serious complication of clavicle fracture, and should be considered in each case of fracture.

- A combined endovascular and open surgical approach to acute traumatic subclavian artery lacerations can be considered in select cases, particularly when complete transection is suspected.

- Endovascular arterial occlusion in acute trauma may help facilitate open arterial repair, by reducing tissue plane distortion and active haemorrhage during dissection.

- In cases of clavicular fracture with underlying acute vascular injury, open vascular repair may be considered more favourably as surgical exposure in the area is already required for clavicular fixation. planes distorts the anatomy, increasing the challenge of open dissection. Stopping haemorrhage with endovascular balloon occlusion reduces this, aiding dissection.

In our case, concurrent open clavicle fixation was indicated to both facilitate vascular exposure, repair and stabilisation to protect the underlying repair. In cases where open surgery for an alternate injury is indicated (such as clavicular fixation), concurrent open arterial repair may be considered more favourably, as minimal additional dissection beyond that required for the clavicular repair may be required in order to access the injured vessel. ${ }^{5}$ Therefore, in this case the requirement for clavicular fixation reaffirmed our decision for a combined approach.

Contributors SA examined the patient and composed the report. DG examined the patient and reviewed the report. PL was a primary operator, and reviewed the report. JK was a primary operator and carer for the patient, and reviewed the report.

Funding The authors have not declared a specific grant for this research from any funding agency in the public, commercial or not-for-profit sectors.

Competing interests None declared.

Patient consent for publication Obtained

Provenance and peer review Not commissioned; externally peer reviewed

Open access This is an open access article distributed in accordance with the Creative Commons Attribution Non Commercial (CC BY-NC 4.0) license, which permits others to distribute, remix, adapt, build upon this work non-commercially, and license their derivative works on different terms, provided the original work is properly cited and the use is non-commercial. See: http://creativecommons.org/ licenses/by-nc/4.0/.

\section{REFERENCES}

1 Kendall KM, Burton JH, Cushing B. Fatal subclavian artery transection from isolated clavicle fracture. J Trauma 2000;48:316.

2 Stockinger ZT, Townsend MC, McSwain NE, et al. Acute endovascular management of a subclavian artery injury. J La State Med Soc 2004;156:262-4.

3 Stryker GmbH. Stryker VariAx clavicle locking plate system, 2015.

4 Castelli P, Caronno R, Piffaretti G, et al. Endovascular repair of traumatic injuries of the subclavian and axillary arteries. Injury 2005:36:778-82.

5 Wang K-qin, Wang Z-gao, Yang B-zhong, et al. Long-term results of endovascular therapy for proximal subclavian arterial obstructive lesions. Chin Med J 2010:123:45-50.

6 Gray K, Beckord B, Moazzez A, et al. A comparative analysis of open versus endovascular techniques for management of non-aortic cervicothoracic arterial injuries. Am Surg 2017;83:1054-8.

7 du Toit DF, Strauss DC, Blaszczyk M, et al. Endovascular treatment of penetrating thoracic outlet arterial injuries. Eur J Vasc Endovasc Surg 2000;19:489-95.

8 Danetz JS, Cassano AD, Stoner MC, et al. Feasibility of endovascular repair in penetrating axillosubclavian injuries: a retrospective review. J Vasc Surg 2005:41:246-54.

9 Karkos CD, Mair R, Markose G, et al. Hybrid procedures combining open and endovascular surgical techniques for the management of subclavian artery injuries. $J$ Trauma 2007;63:107-10.

10 Nakada T-A, Idoguchi K, Fukuma $\mathrm{H}$, et al. Case report: urgent endovascular treatment of subclavian artery injury after blunt trauma. F1000Res 2014:3:310.

Copyright 2021 BMJ Publishing Group. All rights reserved. For permission to reuse any of this content visit

https://www.bmj.com/company/products-services/rights-and-licensing/permissions/

BMJ Case Report Fellows may re-use this article for personal use and teaching without any further permission.

Become a Fellow of BMJ Case Reports today and you can:

Submit as many cases as you like

- Enjoy fast sympathetic peer review and rapid publication of accepted articles

- Access all the published articles

- Re-use any of the published material for personal use and teaching without further permission

Customer Service

If you have any further queries about your subscription, please contact our customer services team on +44 (0) 2071111105 or via email at support@bmj.com.

Visit casereports.bmj.com for more articles like this and to become a Fellow 